\title{
COMPLEXO INDUSTRIAL DA SAÚDE E URBANIZAÇÃO NO ESTADO DE SÃO PAULO'
}

\author{
Medical-industrial complex and urbanization \\ in the State of São Paulo \\ Complexe industriel de la santé et l'urbanisation \\ dans l'état de São Paulo
}

\section{Ricardo Mendes Antas Jr.}

Professor Doutor do Departamento de Geografia da Faculdade de Filosofia, Letras e Ciências Humanas da Universidade de São Paulo (FFLCH/USP).Email: ricardomendes@usp.br

\section{Resumo}

O presente artigo trata da relação entre reestruturação urbana e refuncionalizações do espaço, isto é, como determinadas transformações das formas geográficas no espaço urbano estão ligadas, a longo prazo, a transformações socioespaciais mais amplas. Assim, tomadas em conjunto e somadas às de outros setores da vida da cidade, as refuncionalizações espaciais necessárias à modernização do sistema de saúde no Brasil resultam naquilo que Spósito (2004) denominou reestruturação da cidade. Esta, quando efetivada, implica uma nova relação com as outras cidades que compõem sua rede, criando uma nova relação econômica e política entre as cidades. Consideramos aqui que os circuitos espaciais produtivos e os consequentes círculos de cooperação no espaço (SANTOS; SILVEIRA, 2001) relativos à economia da saúde (indústrias de base química e biotecnologia e indústrias de base mecânica, eletrônica e de materiais) atuam como elementos de nexo entre os dois processos - refuncionalização do espaço e reestruturação urbana -, apontando um caminho de método para os estudos urbanos dedicados ao tema.

Palavras-chave: Reestruturação urbana, refuncionalizações do espaço, complexo industrial da saúde, circuitos espaciais produtivos, círculos de cooperação no espaço.

\footnotetext{
Abstract

The present article addresses the relationship between urban restructuring and space refunctionalizations; that is, how certain transformations of geographical forms in the urban space are connected, in the long term, to broader socio-spatial transformations. Thus, taken together and along with those of other sectors of life in the city, space refunctionalizations necessary for the modernization of the Brazilian health care

O presente artigo busca apresentar uma primeira versão de resultados consolidados da pesquisa que se desdobra desde $2010 \mathrm{e}$ conta com financiamento da Fundação de Amparo à Pesquisa do Estado de São Paulo (Fapesp) desde maio de 2011, intitulada "Reestruturação urbana e refuncionalizações do espaço: o complexo industrial da saúde no Estado de São Paulo e suas relações com a urbanização contemporânea".
} 
system result in what Spósito (2004) calls city restructuring; which, when in place, implies a new relationship with other cities that make up its network, thus creating a new economic and political relationship among the cities. Here, productive spatial circuits and the consequent circles of cooperation in space (SANTOS; SILVEIRA, 2001) pertaining to health-care economics (chemical basic industry and biotechnology, as well as mechanical, electronics and materials basic industries) are considered elements of nexus between both processes - space refunctionalization and urban restructuring - outlining a method for the urban studies focused on this theme.

Keywords: Urban Restructuring; Space Refunctionalizations; Medical-Industrial Complex; Productive Spatial Circuits; Circles of Cooperation in Space.

\section{Résumé}

Cet article traite de la relation entre la restructuration urbaine et les refonctionnalisations de l'espace, autrement dit comment certaines transformations des formes géographiques dans l'espace urbain sont liées, à long terme, aux transformations socio-spatiales plus larges. Ainsi, pris ensemble et ajouté aux autres secteurs de la vie en ville, des refonctionnalisations de l'espace nécessaires pour la modernisation du système de santé au Brésil aboutissant à ce que Sposito (2004) a appelé de restructuration de la ville. Celle-ci, quand accomplie, implique une nouvelle relation avec les autres villes qui composent leur réseau, en créant une nouvelle relation économique et politique entre les villes. Nous considérons ici que les circuits spatiales productifs, et donc les cercles pour la coopération dans l'espace (SANTOS; SILVEIRA, 2001) concernant l'économie de la santé (industries de la biotechnologie de base mécanique, de l'électronique et des matériaux des industries chimiques etc.) agissent comme des éléments de liaison entre les deux processus - refonctionnalisations de l'espace et restructuration urbaine - en indiquant une voie de méthode pour les études urbaines dédiés à ce sujet.

Mots-clé: restructuration urbaine, refonctionnalisation de l'espace, complexe industriel de la santé, circuits spatiaux productifs 


\section{INTRODUÇÃO}

Há hoje no Brasil, a formação bem consolidada de circuitos espaciais produtivos da saúde especializados nos mais diferentes tipos de insumos para clínicas e hospitais. Essa produção industrial requer conhecimento aplicado e pesquisa stricto sensu, instituições públicas e privadas no estabelecimento de elos entre os agentes produtivos e uma logística flexível e sofisticada. Na dinâmica desses circuitos espaciais produtivos da saúde, o hospital situa-se como um sistema técnico e informacional, que se configura num elemento central para essa produção industrial e científica. Esses complexos voltados à chamada concepção de medicina curativa - paradigma dominante na saúde brasileira, mas também alhures -, têm o papel de indutores da urbanização e da transformação das cidades para acolher esses sistemas produtivos centrados no abastecimento do setor de serviços.

A chamada medicina moderna, altamente dependente de tecnologia, é o modelo amplamente adotado nas políticas públicas da maioria dos Estados nacionais, tal como vem sendo desenvolvida no Brasil, desde o momento em que a saúde passa a ser uma pauta concreta das políticas públicas em nosso território. Muitos são os autores na ciência social crítica que apontam esse fato. Na sua geografia urbana histórica, Maurício de Almeida Abreu (1996) indica a origem desse processo quando reflete sobre a chegada da família real ao Rio de Janeiro, em 1808, trazendo o pensamento higienista, que já se desenvolvia no Europa e que serviria de justificativa para operar profundas mudanças no espaço físico e no sistema normativo na cidade fluminense. Já nesse momento o autor apontava a tendência soluções fundadas na soberania técnica, com investimentos consideráveis para o período (ABREU, 1996, p. 158, 160, 163 et passim). Muito brevemente, o Brasil figuraria entre os primeiros países que experimentariam uma "novidade científica" - a vacinação em massa, de que a medicina praticada em muitos dos países ocidentais ainda desconfiava. ${ }^{2}$

O paradigma de tecnologia intensiva na saúde assume especial relevância no território brasileiro a partir da década de 1960, especialmente sob o regime militar e, como em muitas políticas públicas setoriais do período, ele se mostrou altamente excludente, na medida em que o sistema atendia apenas (ou, no melhor dos casos, prioritariamente) a população trabalhadora inserida no emprego formalizado, que apresentava contribuição previdenciária (ALMEIDA, 2005), deixando fora desse serviço parte considerável da população. Após a Constituição de 1988, vemos constituir-se, por força da Carta Magna, o Sistema Único de Saúde (SUS), que tornará o acesso à saúde um direito extensivo a todos os cidadãos. Para dar consequência à lei, passa-se a criar uma série de mecanismos

O exemplo desse embate de concepções na medicina ficou amplamente conhecido no Brasil com a Revolta da Vacina, protagonizada pelo médico Oswaldo Cruz. Ver Benchimol (1990) e também Latour (1997). 
fiscais, bem como fundos específicos de que não cabe tratar aqui, de modo a garantir tal acesso aos serviços de saúde.

O modelo adotado pelo SUS não é exatamente monolítico e tampouco consensual entre os agentes sociais envolvidos em sua construção. Temos sempre que considerar, no mínimo, dois grandes blocos, que lutam diuturnamente para impor seu projeto, que podem ser sintetizados, em linhas gerais, como o da medicina preventiva e o da medicina curativa, esta bastante fundada no emprego de tecnologia de ponta e que tem na instituição hospitalar uma espécie de epicentro. De fato, há muito mais nuances do que essa sumária divisão, estabelecida aqui apenas para indicar a força política e científica do segundo grupo e que é o objeto de fundo do presente texto, para pensarmos a relação entre saúde e urbanização.

Basicamente, a hegemonia da medicina curativa no sistema brasileiro de saúde, que movimenta algo em torno de 10\% do PIB nacional, implica efetivamente a implementação de pesados e sofisticados objetos técnicos em sistema, quase sempre nas cidades e especialmente nas metrópoles, no que toca ao comando político e à administração desse vasto sistema técnico "voltado para a cura". No período atual, esses sistemas especializados se configuram em circuitos espaciais produtivos (SANTOS, 1988; SANTOS; SILVEIRA, 2001), isto é, estruturas que exigem produção de conhecimento, centros de gestão de informação e especializações produtivas (da indústria química, de eletrônicos e da biomedicina, entre outras). Consequentemente, a cidade passa por transformações profundas nas áreas que vieram se especializando ao longo de sua história em fixos de saúde, que, no entanto, ficaram com muitas de suas formas envelhecidas (SANTOS, 1986) no que tange às necessidades dessa nova medicina hegemônica e globalizada, e reclamam mudanças profundas também no espaço urbano, para incorporar a nova lógica do período nesse setor.

É nesse sentido que buscamos apreender uma parte da relação entre as refuncionalizações dos espaços das cidades e da reestruturação urbana por que passa o território como um todo, embora, no que tange à saúde, esse processo seja mais significativo no estado de São Paulo. Nesse contexto, vemos emergirem cada vez mais questões relativas à reestruturação urbana, nas análises que buscam explicar esse processo em consonância com o movimento geral do modo de produção (SPOSITO; SPOSITO, 2012; ELIAS; PEQUENO, 2012; SOJA, 1993; SPOSITO, 2004; 1996; SÁNCHEZ, 2001; LENCIONI, 1994; entre outros), e aqui nos propomos partir da economia da saúde ${ }^{3}$ para identificar determinados elementos espaciais da reestruturação em curso no território brasileiro, assim como compreender os lineamentos e os limites dessa reestruturação, isto é, o que é novo na lógica da produção do espaço urbano e quanto a organização da rede de cidades é afetada por esse processo.

Adotamos aqui a expressão economia da saúde (cf. IBGE, 2008), devido a sua grande complexidade, em detrimento do termo setor. 
Se de fato podemos pensar uma nova estrutura para o espaço urbano, é igualmente inequívoco que essa empreitada não é sem riscos: afinal, a cidade se configura na dinâmica de um processo contínuo de transformação e, em vez de se erigir em nova estrutura, inédita a cada período, reestrutura-se sobretudo em função das novas demandas, decorrentes de modernizações que, embora localizadas, afetam o conjunto do espaço geográfico. Partindo dessa premissa, veremos como os diferentes níveis de refuncionalização dos objetos e sistemas técnicos presentes nas cidades (SANTOS, 1994a; BAUDRILLARD, 1993) constituem o próprio engenho das longas reestruturações urbanas e são responsáveis pela transição de uma estrutura para outra, bem como a consequente manutenção da formação socioespacial brasileira na divisão social e territorial do trabalho mundializada.

Assim, nossa linha de investigação guia-se pelo seguinte princípio: para que o sistema urbano passe a ter uma nova estrutura, é imperativo que a cidade incorpore as funções ditadas pela nova divisão do trabalho nas escalas superiores à formação socioespacial, preparando regiões funcionais para acolherem uma nova lógica. Segundo essa proposição, a criação de regiões com alto grau de conteúdo técnico e informacional, sintonizadas com as lógicas hegemônicas, se daria por meio de refuncionalizações no espaço urbano que acabam por interferir na totalidade da cidade, reestruturando-a (SPOSITO, 2004), e, em seu movimento conjunto, transformam a própria realidade urbana regional e mesmo a do território nacional.

\section{Reestruturação urbana, reestruturação da cidade e refuncionalizações do espaço}

A materialidade do espaço urbano pode ser compreendida como um processo decorrente das formas geográficas acumuladas na história, as quais se traduzem, entre outras coisas, numa quantidade inestimável de objetos produzidos pela força do trabalho humano - os objetos técnicos, segundo Milton Santos (1994b). Esses objetos técnicos, que são concebidos de modo crescentemente sistêmico, constituem a base sobre a qual se produz cotidianamente e também se reinventa a cada período toda a vida social, superando antigas barreiras e atingindo novos contextos espaciais, que se combinam com as situações precedentes.

Tomada em seu conjunto, a cidade apresenta uma dinâmica de transformação incessante. Nela são implementados novos objetos e sistemas técnicos com funções contemporâneas para incorporar as lógicas hegemônicas, tornadas globais no presente período. Influenciados por esse processo, grande parte dos objetos e dos sistemas técnicos que já existiam no espaço urbano são submetidos a refuncionalizações, adequando-se a lógica produtiva da cidade ao movimento geral do modo de produção. 
No caso brasileiro, essa dinâmica é mais evidente numa metrópole como São Paulo, embora parcial ou diferentemente, esse mesmo processo seja constatado nas demais metrópoles, assim como na maioria das grandes e médias cidades brasileiras, como apontam, por exemplo, Spósito e Spósito (2012) e Elias e Pequeno (2012). Por isso, entendemos que se devem analisar as novas funções presentes na metrópole de comando da formação socioespacial brasileira para então tentar compreender o nexo do diálogo entre as cidades em seu conjunto, na região e no território nacional (SOUZA, 1988, p. 4). Só a clareza dos papéis que hoje exercem as cidades no sistema econômico - em âmbito mundial, nacional e regional - nos possibilita definir e caracterizar a reestruturação urbana que atravessamos.

A expressão "reestruturação" faz referência aos períodos em que é amplo e profundo o conjunto das mudanças que orienta os processos de estruturação urbana e das cidades (SPOSITO, 2004, p. 312). Desse modo, a cidade passa antes por refuncionalizações que por reestruturações. Estas constituem cada organização lógica e relacional (HARVEY, 1980) entre os sistemas de cidades, segundo a divisão social e territorial do trabalho de um determinado período, enquanto aquelas revelam a própria dinâmica espacial da cidade. Nesse sentido, entendemos que a reestruturação da cidade - expressão de Maria Encarnação B. Spósito (2004) - decorre do conjunto de uma série de transformações pontuais e reticulares no espaço da cidade, que ocorrem de modo contínuo e paralelo, consideradas aqui como refuncionalizações do espaço. ${ }^{4}$

Como observa Milton Santos, a história da cidade não pode ser confundida com a história do urbano: "O urbano é frequentemente o abstrato, o geral, o externo. A cidade é o particular, o concreto, o interno" (SANTOS, 1994b, p. 69). Quando analisamos o progresso contínuo de produção de formas que se apresentam em cada cidade, torna-se imperioso revelar as funções que elas cumprem em cada período, seja de modo global (uma cidade industrial ou de serviços), seja por setores (zona residencial, comercial, institucional etc.).

A história do urbano obedece a uma periodização específica e interdependente com a periodização da cidade, e os sujeitos de pesquisas se alteram qualitativamente (SANTOS, 1994b, p. 69). Nesse caso, portanto, são os fluxos entre as cidades que nos aduzem a uma periodização. Segundo a qualidade e a quantidade dos fluxos, pode-se apreender a importância das cidades em seu conjunto, definindo-se a posição de cada uma delas na rede urbana. Ademais, dada a mundialização econômica, a direção, a qualidade e a intensidade dos fluxos se institui de modo crescente, como um elemento essencial à análise dos sistemas de cidades.

\footnotetext{
4 É nesse sentido que entendemos a referência da autora às "articulações entre os espaços internos da cidade" (cap. 5, item 5.2 et passim).
} 
Neste momento de capitalismo corporativo, as forças produtivas se desenvolvem em escala planetária. A divisão capitalista do trabalho em escala mundial é de uma profunda especialização produtiva em cada porção do espaço geográfico combinada com uma integração territorial de todo o sistema econômico, em que a simultaneidade torna-se um atributo da competitividade das firmas hegemônicas.

A possibilidade concreta de unificação instantânea de setores industriais, do uso das redes de transporte e de comercialização e do acesso às informações nesses centros estrategicamente distribuídos em determinadas metrópoles (CASTILLO; TREVISAN, 2005) é capaz de influenciar de maneira contundente as decisões das políticas nacionais e de mobilizar rapidamente funcionários e agentes em todo o mundo: "Redes constituem forças produtivas da economia globalizada e expressam fundamentalmente as dinâmicas da circulação do capital” (MOURA, 2009, p. 43). Tudo isso promove as corporações transnacionais a fatores poderosos de uma complexa combinação das forças produtivas, com muitas variáveis e parâmetros operacionais que atuam em numerosos níveis de agregação.

Quando se toma o caso específico dos fixos de saúde e seus insumos, construídos e fornecidos via de regra por corporações, observam-se três grandes grupos empresariais envolvidos: a) a indústria de base química e de biotecnologia; b) indústrias de base mecânica, eletrônica e de materiais; c) prestadores de serviços (ambulatórios, hospitais e serviços de diagnóstico e tratamento). A bibliografia específica sobre a economia da saúde aponta claramente o forte peso que esses grupos de agentes reunidos sob o que Gadelha (2006; 2003; 2002) chamou de complexo industrial da saúde são capazes de exercer sobre o processo de refuncionalização dos espaços da cidade especificamente voltados à adaptação ou à implementação de fixos de saúde e dos sistemas de fornecimento e produção de insumos para esses fixos, concorrendo, ao lado da dinâmica das outras economias urbanas - transporte, habitação, educação etc. - para a reestruturação da cidade (SPOSITO, 2004) e uma consequente e/ou posterior reestruturação urbana.

\section{0 complexo industrial da saúde e a urbanização contemporânea}

No período de globalização, a reestruturação urbana não pode mais ser pensada apenas no nível regional, e nem mesmo a restrição para a escala da formação socioespacial será, em muitos casos, suficiente para considerar os agentes implicados, conforme atestam Spósito e Spósito (2012). A rede de cidades que sofre transformações com a lógica corporativa, componente de destaque na reestruturação em curso, tem muitas vezes relações estreitas com cidades de outros países, ao passo que cidades vizinhas não são atingidas com igual intensidade porque a lógica corporativa é extremamente seletiva. 
Tratando do processo de urbanização dispersa no território brasileiro, Nestor Goulart Reis mostra que os setores de comércio e serviços - na verdade, seus circuitos superiores - conheceram:

[...] mudanças que levaram à adoção de procedimentos até então característicos do setor industrial. Ou seja: concentração empresarial, envolvimento com grandes capitais, atuação em escalas crescentes, com redes de unidades de grandes proporções, planejamento e racionalização das atividades, especialização, conquista de grandes mercados, utilização de marketing também em larga escala e, onde cabe, produção em série (REIS, 2006, p. 140).

Parte significativa da produção científica sobre a economia da saúde vem indicando essa direção apontada por Reis (2006), e acreditamos que o já mencionado conceito forjado por Gadelha (2006; 2003; 2002) é instrumental para a investigação que ora propomos: o complexo industrial da saúde é um novo paradigma que se vem consolidando no país há algumas décadas, com a adoção de uma medicina altamente dependente de tecnologia e de conhecimento científico. Essa opção por um padrão tecnológico elevado tem impactos diretos na transformação da cidade, pois exige fixos de saúde específicos (públicos e privados), demandando especializações nos espaços urbanos voltados à saúde, por meio de uma complexa e profunda divisão social e territorial do trabalho.

Segundo Gadelha, a "noção de complexo industrial da saúde é, a um só tempo, um corte cognitivo, analítico e político". Ele configura um conjunto de atividades produtivas que mantêm relações intersetoriais de compra e venda de bens e serviços e/ou de conhecimentos e tecnologias.

\begin{abstract}
Essas atividades produtivas estão inseridas num contexto político e institucional bastante particular, envolvendo a prestação de serviços como o espaço econômico para o qual flui toda a produção em saúde. Assim, essa atividade está completamente inserida no complexo, tanto por crescentemente se organizar em bases empresariais quanto por configurar o mercado em saúde como construção política e institucional. Isso confere organicidade ao complexo, permitindo articular, num mesmo contexto, a produção de serviços e bens tão diferentes como medicamentos, equipamentos, materiais diversos ou produtos para diagnóstico (2006, p. 15-16).
\end{abstract}

É marcante o impacto do desenvolvimento desses complexos produtivos da saúde sobre as cidades, pois, de modo geral, essa lógica industrial da saúde contemporânea depende da urbanização e privilegia sua implementação nas cidades grandes e médias que têm a presença firme de sistemas hospitalares, especialmente onde existem universidades públicas com ensino e investimento em pesquisa médica e/ou tecnológica, além, é claro, de instalar sua capacidade de comando técnico-financeiro e político dessa extensa rede em franca expansão nas metrópoles mais expressivas das formações socioespaciais, de modo que o resultado desse processo é a produção de uma urbanização corporativa (SANTOS, 1990a), conforme já se desenvolveu alhures, tratando do caso específico da saúde (ANTAS JR.; ALMEIDA, 2011). 
No caso da metrópole paulistana, essas especializações recobrem extensas áreas em diferentes bairros da capital, formando manchas de altos conteúdos de técnica, ciência e finanças, assim como a produção de bens e informações voltados aos serviços de saúde no espaço urbano por meio de pesados investimentos, em parte privados, mas sobretudo públicos.

Num estudo da Fundação Seade de 2010 denominado Ciências da vida humana na cidade de São Paulo, essas áreas foram identificadas como clusters de saúde: Eixo Sul, Eixo Oeste, Eixo Faria Lima, Aglomerado do Tatuapé, Aglomerado de Santana e, principalmente, o Arco da Paulista, onde temos, num extremo, o Quadrilátero da Saúde - o Complexo do Hospital das Clínicas da USP, com a Faculdade de Medicina (FMUSP), a Faculdade de Saúde Pública (FSP-USP), o Instituto do Coração (Incor-HCFMUSP) e o Instituto do Câncer, entre outros - até o Hospital São Paulo, onde estão as instituições de ensino, pesquisa e mesmo produção ligadas à Escola Paulista de Medicina (Unifesp), no outro extremo, na região da Vila Mariana (Mapa 2).

\section{Mapa 1 - Refuncionalizações espaciais voltadas à saúde na cidade de São Paulo: especializações técnico-científicas e produtivas}

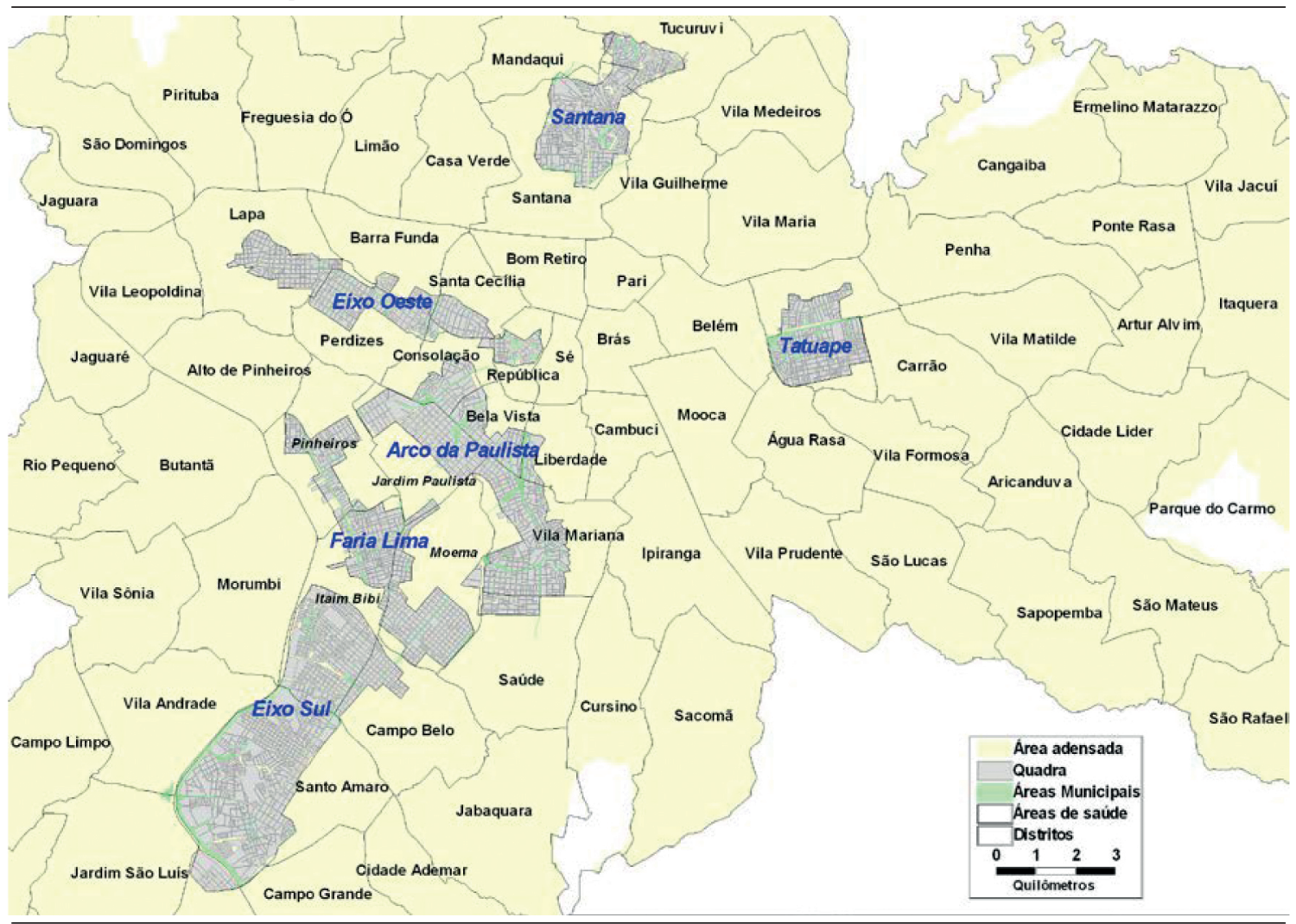

Fonte: Seade (2010, p. 113).

Elaboração do mapa: Gustavo Coelho. 
Em todas as áreas aludidas, se verifica um processo incessante de modificação da cidade, onde bairros predominantemente residenciais foram cedendo terreno a essas especializações voltadas à economia da saúde, transformando-se em bairros mistos, mas com muitas quadras onde predominam atividades dessa economia.

A conformação dessas áreas da cidade especializadas na oferta de serviços e bens voltados à saúde é fruto de um processo mais ou menos longo, dependendo da variável que elegemos: os hospitais-escola e as universidades pertencem aos decursos mais morosos e longos, e aí também podemos incluir alguns tipos de laboratório. Já a grande concentração de consultórios, companhias de seguro-saúde, redes de laboratórios de diagnósticos e determinadas plantas industriais são decorrentes de processos mais recentes e implementados de modo mais acelerado.

No chamado Arco da Paulista, pode-se notar o processo mais intenso de refuncionalização do espaço urbano, pelo qual bairros de alto padrão como Paraíso, Jardim Paulista, Cerqueira César (Jardins e Baixo Augusta), Bela Vista e Consolação, chegando até os bairros de Vila Mariana, Ana Rosa e Vila Clementino, cederam lugar, durante todo século $\mathrm{XX}$, a hospitais, empresas públicas e privadas de serviços de saúde e também a laboratórios, inclusive com alguma produção industrial de fármacos e insumos hospitalares. Todas essas atividades lá se mantêm e se expandem até o presente momento. ${ }^{5}$

\section{Mapa 2 - Arco da Paulista - hospitais e consultórios}
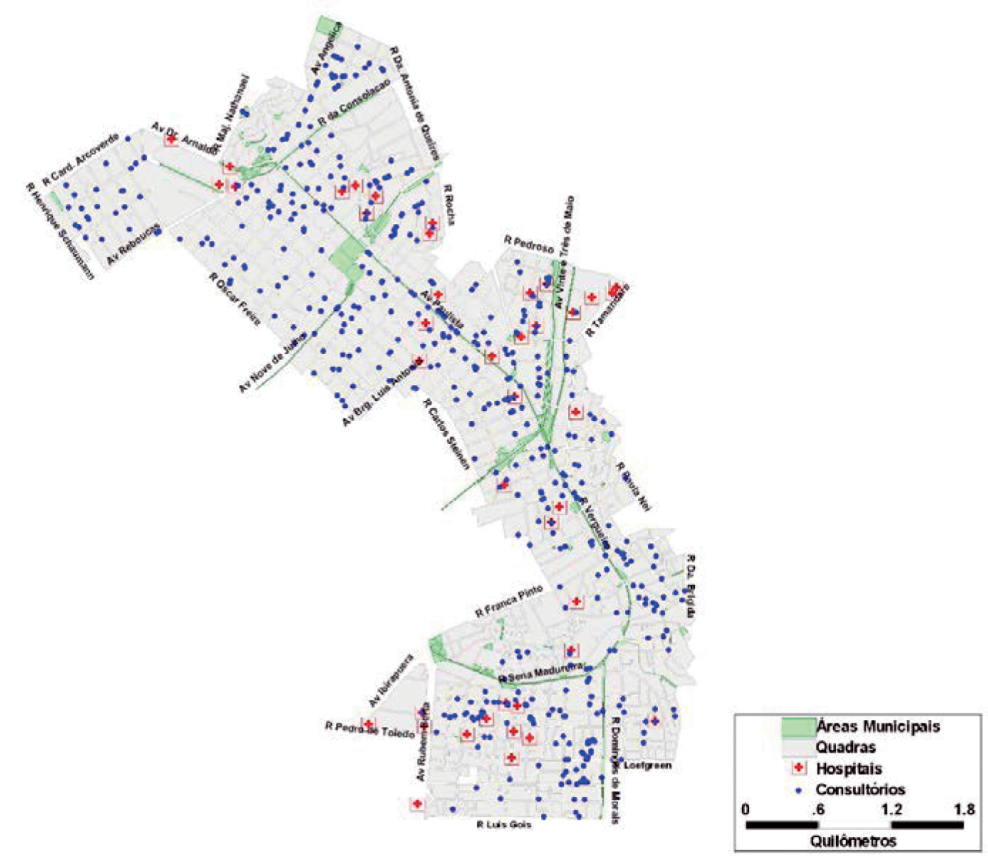

Fonte: Seade (2010, p. 115).

Elaboração do mapa: Gustavo Coelho.

É importante ressaltar que, até os anos de 1970-80, as grandes firmas do setor de serviços financeiros também se dirigiam para essa área, mudando, em parte, para o quadrante sul da cidade nas últimas décadas.

a 
Além da forte concentração de hospitais e consultórios (Mapa 2), é importante apontar que na cidade de São Paulo há muitas outras atividades relacionadas ao escopo de que se trata aqui, das quais selecionamos dois grupos bastante expressivos: (a) em 2008, contavam-se 202 indústrias químicas e farmacêuticas, com significativo número de empresas de grande porte. Destaque-se que a maior parte dessas indústrias estão no Eixo Sul, sobretudo em Santo Amaro e Socorro. Todas as indústrias especializadas em insumos médico-hospitalares perfaziam, no mesmo ano, 412 (Mapas 3 e 4), e pouco mais da metade não ficava dentro dos chamados clusters; (b) em 2010, havia 434 unidades as empresas de diagnose e terapia, comumente conhecidas como laboratórios de diagnóstico, pertencendo a maior parte a grandes empresas estabelecidas em rede por todo o município.

Outro componente essencial para compreendermos a forma que assume o complexo industrial da saúde na capital paulista e como expande sua lógica a toda a rede de cidades relacionadas são o ensino e a pesquisa médicas, elementos centrais e que requerem grandes investimentos, frequentemente públicos mas não exclusivamente, pois é a partir da formação médica que a própria expansão da lógica industrial e tecnológica da saúde tem maior ou menor êxito. Novamente, é no Arco da Paulista que esses elementos se concentram mais, já que aí estão 45 instituições de ensino superior ligadas à saúde em modo geral, com 12.228 vagas de graduação autorizadas e 8 hospitais com residência médica, com 3.000 das 5.000 vagas existentes no município.

Com essa forte presença e crescimento do complexo industrial da saúde em São Paulo, assistimos à expansão gradual dessas atividades para além cidade e mesmo de sua Região Metropolitana, algo um pouco incomum até há duas décadas. Com a difusão dos serviços de saúde, geralmente capitaneados pela presença de hospitais, dá-se uma enorme estratificação da divisão social e territorial do trabalho, que passa pela produção industrial, pelo comércio e pelos serviços de saúde propriamente ditos, mas também por uma outra grande gama de especializações, atingindo por fim o terciário superior, que se estende desde linhas de crédito específicas do BNDES para fortalecimento do complexo industrial da saúde (o conceito acabou por dar o nome ao atual programa de governo, em nível federal, para fortalecer o setor e diminuir a dependência externa, que é um dos maiores déficits atuais da balança comercial) até os serviços de seguro-saúde dos grandes bancos de varejo e de empresas financeiras específicas. 
Mapa 3 - Indústrias de produtos médico-hospitalares na Região Metropolitana de São Paulo em 2008

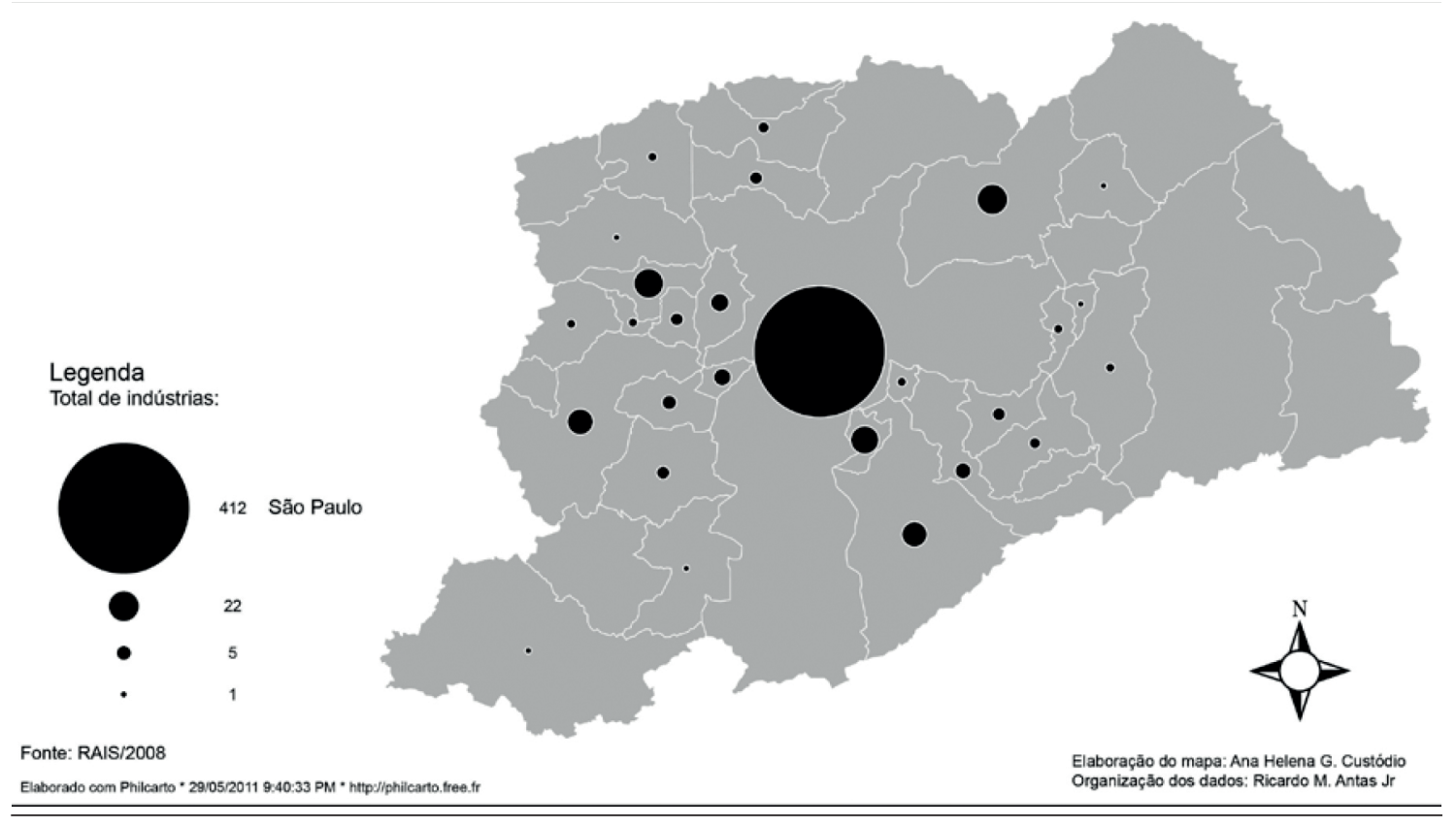

Isso nos dá uma amostra da importância da economia da saúde no processo de expansão urbana, como também das novas formas indutoras de urbanização no território paulista, pois, como afirma Maria Encarnação Beltrão Spósito (2004), as recentes transformações na produção, na distribuição e no consumo - dados essenciais desse complexo industrial da saúde - conduzem ao processo de reestruturação urbana, que se dá conjuntamente com o processo de reestruturação das cidades. 


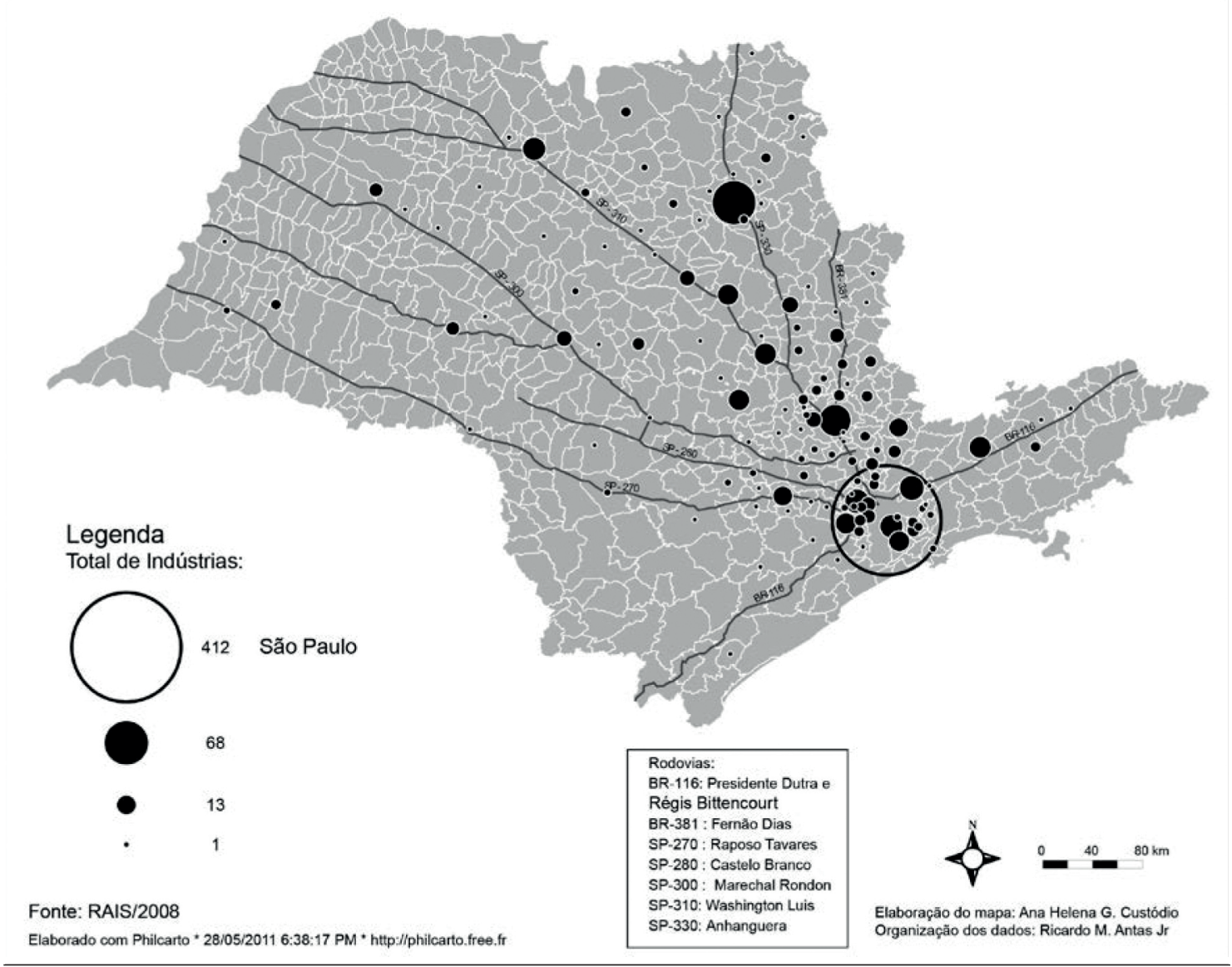

O Mapa 4, de localização das indústrias fornecedoras de produtos hospitalares, é um indicativo da força da metrópole paulistana e das cidades médias nessa rede e mostra como os circuitos espaciais produtivos ligados à economia da saúde são extensos e têm um papel central na urbanização do território paulista.

Esses circuitos espaciais - em conformidade com a economia da saúde cujos dados gerais apresentamos acima -, apresentam alto teor de conhecimento técnico-científico e exigem transformações sócio-espaciais nas cidades onde se instalam, isto é, essa medicina altamente tecnologizada que conhecemos hoje é proporcionalmente dependente da implementação e do aperfeiçoamento dos circuitos espaciais produtivos da saúde, circuitos esses que estabelecem uma relação de reciprocidade entre refuncionalização do espaço e reestruturação urbana.

Os conceitos de circuito espacial da produção e de círculos de cooperação no espaço permitem verificar a interdependência dos espaços produtivos, captando a unidade e a 
circularidade do movimento. Essas noções tornam mais nítidas as contradições espaciais expostas por Santos (1985) e ilustradas pela dialética entre os arranjos espaciais pretéritos e as novas ações e objetos, a organização interna confrontada com os eventos externos e a regulação híbrida (ANTAS JR., 2005) que envolve as ações do Estado, das empresas e da sociedade organizada em torno de interesses comuns.

Desde que a saúde deixou de se apoiar exclusivamente no conhecimento médico, nos consultórios e no uso de fármacos (cuja magnitude era incomparável à atual) e a prática médica passou a contar com inovações tecnológicas de alto valor agregado e volumosos financiamentos públicos especializados, além de corporações dos setores químico, físico-nuclear, financeiro, eletro-eletrônico e biotecnológico, o universo do trato da saúde da população é radicalmente transformado, e se engendra uma nova lógica espacial. Ainda que outrora pudéssemos falar de regiões específicas em determinados países que apresentavam certas especializações produtivas da medicina - e que, inclusive, geraram poderosas economias, eram casos mais ou menos isolados no chamado "centro do sistema".

Com os circuitos espaciais produtivos de saúde, o que vemos é uma nova lógica produtiva voltada a um serviço específico e que não está confinado de modo excepcional a esta ou àquela região, mas trata-se de uma nova lógica que se dá juntamente com a mundialização do capital:

Os circuitos espaciais de produção pressupõem a circulação de matéria (fluxos materiais) no encadeamento das instâncias geograficamente separadas da produção, distribuição, troca e consumo de um determinado produto, num movimento permanente; os círculos de cooperação no espaço, por sua vez, tratam da comunicação, consubstanciada na transferência de capitais, ordens e informação (fluxos imateriais), garantindo os níveis de organização necessários para articular lugares e agentes dispersos geograficamente, isto é, unificando, através de comandos centralizados, as diversas etapas, espacialmente segmentadas, da produção (CASTILLO; FREDERICO, 2010, p. 6).

É nesse sentido que observamos, nos centros urbanos mais dinâmicos, a instalação desses núcleos de comando da economia da saúde (produção de informações, mas também de financiamentos e grupos organizacionais de saúde - seguros, consultorias especializadas, convênios, organizações civis, cooperativas etc.), que se propagam de modo variável por boa parte da rede de cidades, em diferentes graus de aceleração.

Os circuitos espaciais produtivos da saúde tendem a um grau crescente de racionalidade e se expandem de modo mais e mais homogêneo. Com isso, temos um rebatimento no padrão de urbanização, no que tange aos serviços de saúde, pelo qual eles se instalam 
para expandir sua rede. Ao longo de um processo, a consolidação e expansão do complexo industrial da saúde e seus respectivos circuitos espaciais produtivos concorrem de modo significativo para a reestruturação urbana que se desenrola no território.

\section{Refuncionalização do espaço urbano na instalação de fixos de saúde e reestruturação urbana}

As cidades, e em especial as grandes cidades, têm um intenso dinamismo, gerado pelo trabalho de manutenção, remodelagem e criação cotidiana de toda sorte de sistemas técnicos urbanos, encarregados de garantir funções específicas. A produção e a circulação de mercadorias, os serviços privados e públicos, o lazer e as condições de moradia estão condicionados à qualidade e à atualidade dos equipamentos correspondentes a cada um dessas economias urbanas, que apresentam um funcionamento sistêmico e integrado.

Desse modo, a rotina da cidade é plena de transformações nos objetos que a compõem. A ampliação da rede de esgotos, o recapeamento de vias, a recuperação de edifícios, as adaptações paisagísticas etc. são pequenas mudanças que só se fazem sentir quando se as toma numa perspectiva de conjunto, num determinado período. Tais intervenções são fundamentais na prevenção de um "envelhecimento" precoce e da "erosão moral" das formas, visto que o velho - diferentemente do antigo preservado - é frequentemente discriminado e descartado na sociedade moderna (RAYMOND, 1984, p. 140-142/170/173).

Assim, há uma dinâmica contínua no espaço urbano que desemboca em diferentes situações: algumas formas se renovam constantemente, outras são mais duradouras, e há as que desaparecem para ceder lugar a sistemas inéditos. Nesse caso, temos uma outra sorte de transformações, cuja relação com a organização interna da cidade é mais ambígua, pois determinadas intervenções não respondem às necessidades imediatas e tampouco se restringem aos interesses dos agentes locais.

Trata-se de vetores externos, ${ }^{6}$ ligados às características da divisão social e territorial do trabalho em escalas superiores ao lugar, as quais reclamam modificações mais ou menos estruturais, mas nunca de modo completo e acabado, dado que a materialidade presente já tem papel ativo na economia, na cultura e na política. Desse modo, existe uma tensão entre essas instâncias para acompanhar a ordem nova de cada período histórico na escala da economia mundo - usando os termos de Fernand Braudel (1985) em La dynami-

\footnotetext{
Segundo Milton Santos, horizontalidades e verticalidades são recortes espaciais superpostos, ao mesmo tempo condicionados e condicionantes da solidariedade organizacional, principal elemento de formação das regiões contemporâneas. Tal solidariedade tanto pode se dar a partir de contiguidades e continuidades como de ações empreendidas a partir de pontos distantes, mas não isolados. Ambas estão sempre sujeitas às leis do movimento (SANTOS, 1994b): "Uma formação social não pode ser estudada sem que sejam considerados aqueles dois conjuntos de relações definidos, há tempos, por Lênin: as relações horizontais e as relações verticais. As relações horizontais nos dão a estrutura interna da sociedade, as relações verticais nos indicam as relações de uma sociedade com as outras sociedades" (SANTOS, 1986, p. 200).
} 
que du capitalisme -, na medida em que as inovações supõem uma redefinição dos papéis dos agentes e mesmo a obsolescência de algumas funções. Logo, esse período transitório é marcado por uma instabilidade entre os que conduzem as modernizações para acolher os vetores externos e aqueles que são direta ou indiretamente afetados por essas decisões.

No estudo das refuncionalizações ocorridas numa cidade, é fundamental que se conheçam os períodos de modernização definidos pela implementação de objetos que, em conjunto, têm seus níveis técnicos identificáveis como pertencentes a uma mesma geração (RAYMOND, 1984; BAUDRILLARD, 1993). Cada geração técnica permite o delineamento de um período ou subperíodo da história da cidade. Portanto, a refuncionalização do espaço é intrinsecamente ligada à história das formas: as que desapareceram, aquelas das quais restam apenas resíduos e as que assumiram novos papéis em razão de outras recém-criadas (SANTOS, 1994b, p. 69).

É assim que a cidade, em seu funcionamento sistêmico, permanece sempre apta a acolher o nexo da divisão social e territorial do trabalho, garantindo a realização material da sociedade local e/ou regional na história, ou seja, criando condições para receber a energia que dá vida e força às economias de mercado, abertas e expansionistas por definição (BRAUDEL, 1985). Hoje, a força motriz que alimenta a acumulação se constitui da produção, da gestão e do armazenamento de informações (SANTOS, 1997), e essa tem sido a causa da transformação das principais metrópoles do mundo - erigidas outrora em função da indústria, agora, metrópoles terciárias.

Hoje, graças às possibilidades técnicas do período, o trabalho pode ser repartido entre muitos lugares, de acordo com sua produtividade para certos produtos. Isso leva a refuncionalizar áreas com grandes densidades pretéritas e a ocupar outras até então rarefeitas. Em todos os casos, modifica-se o valor de cada pedaço do território e aumenta a cooperação (SANTOS; SILVEIRA, 2001, p. 141).

Em seu processo histórico, algumas cidades perderam importância no contexto mais amplo de sua época ou desapareceram em função de não ter renovado suficientemente suas formas; em outros termos, a cidade não se proveu de objetos e sistemas técnicos que assegurassem sua participação na divisão social e territorial vigente do trabalho.

Mas, se o desaparecimento de cidades é hoje um fato raro, em razão do processo de urbanização que atinge todos os continentes - dado o papel renovado do espaço urbano na realização da economia mundializada, em que a concentração de recursos humanos e técnicos é uma necessidade (LEFEBVRE, 2008) -, a falência de alguns subespaços das grandes cidades, via de regra seus antigos centros econômicos, é um processo frequente. Esse fenô- 
meno tem sua causa principal na não adaptação de uma porção territorial dessincronizada com as temporalidades hegemônicas contemporâneas. Com isso, esses centros conheceram muito rapidamente o envelhecimento seguido de abandono (JACOBS, 2000, p. 268-276).

A relação aqui estabelecida entre refuncionalização e reestruturação implica o reconhecimento das relações recíprocas de influência da cidade com a rede de cidades. Podem-se, então, estabelecer relações entre a cidade e a região ou entre as cidades e a formação socioespacial. Em ambos os casos, trata-se das ações deliberadas na transformação do papel predominante da cidade e do rebatimento nos elementos urbanos que compõem o território em suas variadas escalas. Os limites da refuncionalização do espaço se devem ao poder de comando desta ou daquela cidade sobre o território.

Com o auxílio da ciência, sobretudo após a Segunda Guerra Mundial, há uma maior combinação entre ações deliberadas e ações espontâneas (SANTOS, 1990a). As primeiras vêm acompanhadas de cálculo e previsão, com o objetivo de realizar um concerto no território para um aproveitamento ótimo pelas grandes empresas nacionais e transnacionais e para a regulação social necessária à justificação do Estado.

O grupo das ações espontâneas também mede e prevê, mas numa escala mais imediata. Pode-se dizer que, paralelamente à subordinação imposta pelo grupo de ações deliberadas, de novas lógicas de produção da vida material, há também resistência e luta, na maioria das vezes não organizadas; às vezes, sim, mas poucas vezes articuladas globalmente.

O território, então, é uma combinação entre o que é deliberadamente concebido grandes modernizações, implementação de sistemas técnicos que abrangem várias escalas e fazem interagir as regiões e as cidades, integrando-as -, promovendo novos usos dos recursos sociais e naturais que o compõem, e o que é recriado pela tensão entre a necessidade e o desejo de todos, da maioria. É esse, enfim, o modo como o território é definitivamente usado (SANTOS, 1994b), pois as refuncionalizações planejadas nunca atingem de modo pleno a dinâmica e a pluralidade dos anseios e das necessidades da sociedade.

Por maior que seja a modernização a ser implementada numa cidade, devido à ação de interesses econômicos hegemônicos, uma grande área que se inova ou mesmo a implementação de um amplo sistema técnico de transporte, saúde ou educação, sempre se tratará, em casos semelhantes, de uma refuncionalização do espaço. Isso porque é sempre uma parte da cidade que conhece tal intervenção, que já tem uma dinâmica espacial, derivada de modernizações de várias idades e que atuam em conjunto, e várias idades de divisões territoriais do trabalho que são mais ou menos autônomas e que cooperam com menos ou mais intensidade. 
Determinadas modernizações que operam objetivamente transformações no espaço de determinadas cidades, intersecções privilegiadas nos fluxos da rede urbana, são tão poderosas que afetarão o conjunto do espaço urbano. E, a longo prazo, tocam o próprio processo de urbanização, na medida em que se institui uma nova lógica de relação entre as cidades e as regiões produtivas.

Esse seria o caso da cidade de São Paulo hoje, quando os fluxos de informação passaram a ser produzidos e geridos de modo inédito, com a transformação técnica e normativa do setor de serviços financeiros e o advento da informação monetária (SANTOS, 2000; KURTZMAN, 1995). Nesse caso, temos a transformação do urbano a partir da refuncionalização de um sistema (o financeiro), que implicou uma refuncionalização espacial (FIX, 2007).

Outros tipos de refuncionalização concorrem para a reestruturação da cidade (SPOSITO, 2004). É o caso da transformação de um sistema de transportes, como a expansão de padrões técnicos existentes somados a novos, eventualmente, e mudanças organizacionais. Com a adoção do bilhete único, por exemplo, alteram-se as possibilidades de circulação e das localizações. Tudo isso, ao termo de um certo período, somado a outras transformações em paralelo (na educação, na moradia, na saúde), acaba por promover a reestruturação da cidade.

É nesse sentido que as refuncionalizações espaciais são responsáveis por incorporar a mudança de padrão tecnológico e organizacional da saúde em São Paulo, e estão concorrendo com outros setores em transformação para a reestruturação da cidade e para a reestruturação urbana.

A mudança de padrão tecnológico que vem ocorrendo aceleradamente na economia da saúde no Brasil, da qual, como aponta ALMEIDA (2005), a criação do SUS é um forte marco institucional que possibilita a incorporação das inovações de tecnologia de ponta aplicadas ao combate de doenças, tem um forte papel de reorganização espacial que afeta parte de uma metrópole ou grande cidade e até mesmo a rede de cidades em seu conjunto.

À medida que se aprofunda o padrão tecnológico por meio de novos complexos hospitalares - mais investidos de conhecimento científico aplicado, mas também de novos capitais corporativos e novas instituições (públicas e privadas) para financiamento e gestão desses novos fixos de saúde que dão possibilidades de cura e tratamento de alto padrão tecnológico -, temos transformações significativas no espaço urbano, pois estas implicam, ainda que pontualmente, mudanças no espaço construído (chegando a atingir a circulação, o perfil de ocupação das classes de renda média e alta, a renda do 
solo urbano etc.) e também novas especialidades e movimentação de pequenos e médios capitais oferecendo novos serviços - que não se desligam dos complexos hospitalares e de suas ofertas especializadas.

E assim, sucessivamente, vamos observando mudanças nas funções locais dos objetos e sistemas técnicos: prédios de moradia vão cedendo lugar a consultórios e pequenos laboratórios, comércios gerais se especializam em serviços de saúde e afins e surgem instituições públicas e privadas dependentes de proximidade dos complexos hospitalares e dos locais de trabalho da corporação médica. Entre muitos, esses são alguns exemplos, até o momento em que essas mudanças atinjam uma escala regional, isto é, uma grande área da metrópole e mesmo um conjunto significativo da rede de cidades.

Assim, há um movimento mais geral dessa especialização regional na cidade, numa economia altamente elaborada e complexa da saúde, com uma certa "replicação" dessa lógica em outras cidades da mesma rede, com indústrias que tiram vantagem da proximidade geográfica, assim como é o caso de muitos serviços, notadamente o de diagnósticos, que acabam por gerar um amplo movimento de novas formas de urbanização, transformando a composição de classes sociais com valorização e especialização do espaço urbano, apontando as tendências daquilo que Santos (1990b) denominou urbanização corporativa. Combinado com outras economias urbanas, esse processo de refuncionalizações espaciais motivadas pela economia da saúde revela o movimento das cidades, que se desloca de um padrão de urbanização a outro, isto é, responde às novas necessidades criadas pelo novo momento histórico.

Esse processo corresponde ao movimento da reestruturação urbana, uma dinâmica paulatina, que se desdobra pela transformação nos conteúdos das formas preexistentes e também pela inclusão de novas formas, correspondentes à totalidade atualizada. É o movimento de totalização do espaço geográfico (SANTOS, 1979, p. 153-167).

\section{CONSIDERAÇÕES FINAIS}

Vê-se assim como o estudo dos circuitos espaciais produtivos se constitui em referencial teórico para analisar as economias políticas da cidade e da urbanização estabelecendo-lhes uma integração e relacionando-as num mesmo momento de totalização. É também, portanto, um caminho de método geográfico para compreender as relações entre lugar e formação socioespacial e destes com a globalização. 
Como são planetários, os circuitos espaciais produtivos levam aos lugares onde se instalam a racionalidade organizacional do capitalismo contemporâneo, cindindo as solidariedades orgânicas das cidades e provocando, assim, desordem e novas ordenações territoriais (e também jurídicas) que interferem em toda a dinâmica social. Quando a economia da saúde no território brasileiro conhece a formação dos circuitos espaciais produtivos, muda a própria prática médica (MOTA; MARINHO, 2011; NOGUEIRA, 2007). Uma das principais mudanças nas práticas é a instalação da lógica corporativa, que vai rapidamente substituir o conhecimento abarcante da formação médica pela especialização radical. Tais especializações nas faculdades de medicina se tornam aceleradamente dependentes das corporações e de seus produtos com altos níveis de racionalidade científica, investimento técnico e financeiro que só um capital global tem sido capaz de desenvolver e comercializar.

Aliás, um tema importante para a geografia - e de que não tratamos aqui - é compreender como se dão as coações de marketing próprias da economia da saúde. Alguns textos clássicos e atuais desse campo de conhecimento que se tornou a saúde apontam os hospitais e a própria formação médica como focos de muitas estratégias corporativas para ampliar mercados (NOGUEIRA, 2007; PORTER, 2004; STARR, 1991; CORDEIRO, 1980; PESSOA, 1978), produzindo um sistema de convencimento e de necessidades fundamentais às novas concepções de cura e de combate aos males.

Não é apenas o combate dos males que muda na medicina. Os circuitos espaciais produtivos, imperativos dessa lógica, vão demandar modernizações profundas no espaço geográfico. Vemos assim grandes investimentos de capital na refuncionalização dos espaços das cidades para acolher e expandir a lógica corporativa. Como não é só a economia da saúde que sofre essa intervenção da ação corporativa, mas todas as economias urbanas, ao longo desse processo, ele transforma o próprio o padrão de urbanização, tangendo, em médio e longo prazo, a estrutura de redes de cidades.

\section{REFERÊNCIAS}

1. ABREU, Maurício de Almeida. Pensando a cidade no Brasil do passado. In: CASTRO, I. E.; GOMES, P. R. C. C.; CORRÊA, R. L. (Orgs.). Brasil: questões atuais da reorganização do território. Rio de Janeiro: Bertrand Brasil, 1996. p. 145-184.

2. ALMEIDA, Eliza. Uso do território brasileiro e os serviços de saúde no período técnico-científico-informacional. Tese (Doutorado em Geografia Humana) - Departamento de Geografia, Faculdade de Filosofia, Letras e Ciências Humanas, Universidade de São Paulo, São Paulo, 2005. 
3. ANTAS JR., R. M. Território e regulação: espaço geográfico, fonte material e não formal do direito. São Paulo: Humanitas, 2005.

4. Elementos para uma discussão epistemológica sobre a regulação do território. Geousp, São Paulo, n. 16, p. 81-86, 2004.

5 . . Refuncionalização do espaço e nova rede de cidades: uma contribuição para os estudos de reestruturação urbana. Projeto Alfa-Reub: relatório de pesquisa. Université Paris 1 (Panthéon-Sorbonne), Sorbonne, 1998.

6. ; ALMEIDA, E. P. Os serviços de saúde no Estado de São Paulo: seletividades geográficas e fragmentação territorial. In: MOTA, A.; MARINHO, M. G. S. M. C. (Orgs.). Práticas médicas e de saúde nos municípios paulistas: a história e suas interações. São Paulo: USP/Faculdade de Medicina/Casa de Soluções e Editora, 2011.p. 281-295. (Medicina, Saúde e História.)

7. ARROYO, M. Território nacional e mercado externo: uma leitura do Brasil na virada do século XX. Tese (Doutorado em Geografia Humana) - Departamento de Geografia, Faculdade de Filosofia, Letras e Ciências Humanas, Universidade de São Paulo, São Paulo, 2001.

8. BAUDRILLARD, Jean. O sistema de objetos. São Paulo: Perspectiva, 1993.

9. BENCHIMOL, Jaime. Domingos José Freire e os primórdios da bacteriologia no Brasil. História, Ciências, Saúde - Manguinhos, Rio de Janeiro, v. 2, n. 1, p. 67-98, mar./jun. 1995.

10. BRAUDEL, Fernand. La dynamique du capitalisme. Paris: Champs/Flammarion, 1985.

11. CASTILLO, R.; FREDERICO, S. Espaço geográfico, produção e movimento: uma reflexão sobre o conceito de circuito espacial produtivo. In: PEREIRA, M. F. V. (Org.). Território: ensaios teóricos e temas contemporâneos. Uberlândia: UFU, 2010.

12. CASTILLO, R.; TREVISAN, L. Racionalidade e controle dos fluxos materiais no território brasileiro: o sistema de monitoramento de veículos por satélite no transporte rodoviário de carga. In: DIAS, Leila C. et al. (Orgs.). Redes, sociedades e territórios. Santa Cruz do Sul: Edunisc, 2005.

13. CORDEIRO, H. A indústria da saúde no Brasil. Rio de Janeiro: Graal, 1980.

14. ELIAS, Denise; PEQUENO, Renato. Reestruturação econômica e urbana em uma cidade média do semiárido brasileiro. Revista da ANPEGE, v. 8, n. 9, p. 15-27, 2012.

15. FIX, Mariana. São Paulo cidade global: fundamentos financeiros de uma miragem. São Paulo: Boitempo, 2007.

16. GADELHA, Carlos Augusto Grabois. Desenvolvimento, complexo industrial da saúde e política industrial. Revista de Saúde Pública, São Paulo, v. 40, p. 11-23, ago. 2006. Número especial.

17. ___ O complexo industrial da saúde e a necessidade de um enfoque dinâmico na economia da saúde. Ciência \& Saúde Coletiva, v. 8, n. 2, p. 521-535, 2003. Disponível em: <http:// www.scielo.br/pdf/csc/v8n2/a15v08n2.pdf>. Acesso em: 12 maio 2013.

18. Complexo da saúde. In: COUTINHO, L. G.; LAPLANE, M. F.; KUPFER, D.; FARINA, E. (Coords.). Projeto Estudo de Competitividade por Cadeias Integradas: relatório de pesquisa. Cidade: Núcleo de Economia Industrial e da Tecnologia do Instituto de Economia/ Camp/MDIC/ MCT/Finep, 2002. 
19. HARVEY, David. A justiça social e a cidade. São Paulo: Hucitec, 1980.

20. IBGE. Economia da saúde: uma perspectiva macroeconômica 2000-2005. Estudos \& Pesquisas: informação econômica. Ministério do Planejamento. Orçamento e Gestão. Diretoria de Pesquisas Coordenação de Contas Nacionais, Rio de Janeiro, 2008.

21. IBGE. Estatísticas da Saúde Assistência Médico-Sanitária. Ministério do Planejamento, Orçamento e Gestão. Diretoria de Pesquisas Coordenação de População e Indicadores Sociais, Rio de Janeiro, 2006.

22. JACOBS, Jane. Morte e vida das grandes cidades. São Paulo: Martins Fontes, 2000.

23. KURTZMAN, Joel. A morte do dinheiro: como a economia eletrônica desestabilizou os mercados e criou o caos financeiro. São Paulo: Atlas, 1995.

24. LABASSE, Jean. La ciudad y el hospital: geografía hospitalar. Madrid: Instituto de Estudios de Administración Local, 1982.

25. LANGENBUCH, Jurgen Richard. A estruturação da Grande São Paulo: estudo de geografia urbana. São Paulo: Biblioteca Geográfica Brasileira, 1971.

26. LATOUR, Bruno. Ciência em ação. São Paulo: Editora da Unesp, 2000.

27. LATOUR, Bruno. A vida de laboratório: a produção dos fatos científicos. Rio de Janeiro: Relume Dumará, 1997.

28. LEFEBVRE, Henri. Espaço e política. Belo Horizonte: Editora da UFMG, 2008.

29. LENCIONI, Sandra. Reestruturação urbano-industrial no estado de São Paulo: a região da metrópole desconcentrada. Espaço \& Debates. São Paulo, n. 38, p. 54-61, 1994.

30. LIMA, Nísia Trindade (Org.). Saúde e democracia: história e perspectiva do SUS. Rio de Janeiro: Fiocruz, 2005.

31. LIMONAD, E.; HAESBAERT, R.; MOREIRA, R. Brasil século XXI: por uma nova regionalização? São Paulo: Max Limonad, 2008.

32. MINISTÉRIO DA SAÚDE. Avaliação do Ministério da Saúde indica aumento dos acidentes. Secretaria de Vigilância em Saúde em Rede. Ministério da Saúde, n. 27, mar. 2007.

33. MOTA, A.; MARINHO, M. G. S. M. C. (Orgs.). Práticas médicas e de saúde nos municípios paulistas: a história e suas interações. São Paulo: USP/Faculdade de Medicina/Casa de Soluções e Editora, 2011. (Medicina, Saúde e História.)

34. MOURA, Rosa. Arranjos urbano-regionais no Brasil: uma análise com foco em Curitiba. Tese (Doutorado em Produção e Transformação do Espaço Urbano e Regional) - Universidade Federal do Paraná, Curitiba, 2009.

35. NOGUEIRA, R. P. Do físico ao médico moderno: a formação social da prática médica. São Paulo: Editora da UNESP, 2007.

36. PESSOA, S. Ensaios médico-sociais. São Paulo: CEBES/HUCITEC, 1978.

37. PORTER, R. Das tripas coração. Rio de Janeiro: Record, 2004. 
38. RAYMOND, Henri. L'architecture, les aventures spatiales de la raison. Paris: CCI/Centre Georges Pompidou, 1984.

39. REIS FILHO, Nestor Goulart. Metropolização em São Paulo. São Paulo: FAU/USP, 1971.

40. RIBEIRO, Luis César de Q. (Org.). O futuro das metrópoles: desigualdades e governabilidade. Rio de Janeiro: Revan, 2000.

41. ROLNIK, Raquel. A cidade e a lei: legislação política urbana e territórios na cidade de São Paulo. São Paulo: Studio Nobel, 1997.

42. SÁNCHEZ, Fernanda. A reinvenção das cidades na virada de século: agentes, estratégias e escalas de ação política. Revista de Sociologia e Política, São Paulo, n. 16, p. 31-49, jun. 2001.

43. SANTOS, Milton. Por uma outra globalização. Rio de Janeiro: Record, 2000.

44. __ Sociedade e espaço: a formação social como teoria e como método. Boletim Paulista de Geografia, São Paulo: Associação dos Geógrafos Brasileiros, Seção São Paulo, , n. 54, p. 81-100, jun. 1997.

45. __ Por uma economia política da cidade. São Paulo: Hucitec/Educ, 1994a.

46. ___ Técnica espaço tempo: globalização e meio técnico-científico-informacional. São Paulo: Hucitec, 1994b.

47. __ A metrópole: modernização, involução e segmentação. In: VALLADARES, L.; PRETECEILLE, E. Reestruturação urbana: tendências e desafios. São Paulo: Nobel/Iuperj, 1990a.

48. Metrópole corporativa e fragmentada: o caso de São Paulo. São Paulo: Nobel, 1990b.

49. ___ Metamorfoses do espaço habitado. São Paulo: Hucitec, 1988.

50. __ Por uma geografia nova. 3. ed. São Paulo: Hucitec, 1986.

51. ___ Espaço e método. São Paulo: Nobel, 1985.

52. ___ Espaço e sociedade. Petrópolis: Vozes, 1982.

53. ____ Economia espacial: críticas e alternativas. São Paulo: Hucitec, 1979.

54. ___ _ SILVEIRA, María Laura. O Brasil: território e sociedade no início do século XXI. Rio de Janeiro/São Paulo: Record, 2001.

55. SEADE. Ciências da vida humana na cidade de São Paulo. São Paulo: Fundação Seade/Île de France/PMSP/ESP, 2010. Disponível em: <http://www.seade.gov.br/projetos/cienciasdavida/ index.php?menu=1>. Acesso em: 15 maio 2013.

56. SILVA, Adriana M. B. A contemporaneidade de São Paulo: a produção e o novo uso do território brasileiro. Tese (Doutorado em Geografia Humana) - Departamento de Geografia, Faculdade de Filosofia, Letras e Ciências Humanas, Universidade de São Paulo, São Paulo, 2001.

57. SOJA, Edward. Geografias pós-modernas: a reafirmação do espaço na teoria social crítica. Rio de Janeiro: Zahar, 1993. 
58. SOUZA, Doriane P. Ferraz. Estudo exploratório da atenção de alta complexidade prestada pelos hospitais do Sistema Único de Saúde. Dissertação (Mestrado em Gestão de Sistemas e Serviços da Saúde) - Escola Nacional de Saúde Pública, Fundação Oswaldo Cruz, Rio de Janeiro, 2004.

59. SOUZA, Maria Adélia de. Governo urbano. São Paulo: Nobel, 1988.

60. SPOSITO, M. E. B.; SPOSITO, E. S. Reestruturação econômica, reestruturação urbana e cidades médias. In: Seminário Internacional RII (Red Iberoamericana de Globalização e Território), XII, 2012. Belo Horizonte: CEDEPLAR/UFMG, 2012.

61. SPOSITO, Maria Encarnação Beltrão. O chão em pedaços: urbanização, economia e cidades no estado de São Paulo. Tese (Livre-docência em Geografia) - Universidade Estadual Paulista, Presidente Prudente, 2004.

62. ___ Reestruturação da cidade. In: MELO, Jayro Gonçalves (Org.). Região, cidade e poder. Presidente Prudente: GAsPERR/Unesp, 1996. p. 111-126.

63. STARR, P. La transformación social de la medicina en los Estados Unidos de América. Cidade do México: Fundo de Cultura Económica, 1991.

64. VELTZ, Pierre; SAVY, Michel (Orgs.). Économie globale et reinvention du local. Paris: Datar/Éditions L’Aube, 1995. 